AsCLePIO. Revista de Historia de la Medicina y de la Ciencia

66 (2), julio-diciembre 2014, p062

ISSN-L:0210-4466

http://dx.doi.org/10.3989/asclepio.2014.26

\title{
LA LUCHA POR LA SUPERVIVENCIA DE LA EMBRIOLOGÍA EN UNA INSTITUCIÓN PRIVADA EN LA ESPAÑA DEL SIGLO XX: LAS CRISIS DEL INSTITUT BIOLÒGIC DE SARRIÀ
}

\author{
Raúl Velasco Morgado \\ Universidad de Salamanca \\ raulvmorgado@hotmail.com
}

Recibido: 6 septiembre 2013; Aceptado: 28 marzo 2014.

Cómo citar este artículo/Citation: Velasco Morgado, Raúl (2014), "La lucha por la supervivencia de la embriología en una institución privada en la España del siglo XX: las crisis del Institut Biològic de Sarrià", Asclepio, 66 (2): p062. http://dx.doi.org/10.3989/ asclepio.2014.26

RESUMEN: Durante el primer tercio del siglo XX, el jesuita Jaime Pujiula Dilmé (1869-1958) dominó con una autoridad casi clásica el cultivo de la embriología en nuestro país. El gran éxito de su proyecto personal, el Institut Biològic de Sarrià, sufrió un primer revés durante la II República con la llegada del gobierno de Azaña al poder. La Compañía de Jesús fue disuelta y sus bienes confiscados. El religioso, no obstante, fue capaz de solventar esta crisis mediante un acuerdo con la Societat Medicofarmacèutica dels Sants Cosme i Damiá, en cuyas dependencias volvió a montar su instituto. Más difícil resultó sobrevivir a la crisis vivida durante la Dictadura Franquista. La edad del Padre y su fuerte personalidad, autoritaria y personalista, dificultó la creación de una escuela a su alrededor. El medro de uno de sus colaboradores, el Padre Joan Puiggrós Sala (1899-¿?), significó la desaparición progresiva de la embriología en el centro y la ocupación del nicho que ésta iba dejando por la bacteriología aplicada, mucho más rentable económicamente en aquellos tiempos de penurias.

PALABRAS CLAVE: embriología; bacteriología; Jaime Pujiula Dilmé; Joan Puiggrós Sala; siglo XX.

\section{THE STRUGGLE FOR SURVIVAL OF EMBRYOLOGY IN A PRIVATE INSTITUTION IN THE 20TH CENTURY SPAIN: THE CRISIS OF THE "INSTITUT BIOLÒGIC DE SARRIÀ"}

\begin{abstract}
During the first third of the twentieth century, the catalan jesuit Jaime Pujiula Dilmé (1869-1958) dominated with an almost classical authority the cultivation of embryology in Spain. The great success of his personal project, the "Institut Biològic de Sarriä", suffered a first setback in the II Republic with the arrival of Azaña's government to power. The Society of Jesus was dissolved, and their property confiscated. Pujiula, however, was able to overcome this crisis with an agreement with the Societat Medicofarmacèutica dels Sants Cosme i Damiá, in whose offices he remounted his institute. More difficult was to survive the crisis experienced during the Francoist dictatorship. The age of the director and his tough personality, authoritarian and personalistic, hindered the creation of a school around him. The thrive of one of his aides, Father Joan Puiggrós Sala (1899-i?), meant the phasing of embryology in the center and the occupation of it niche by his specialty, applied bacteriology, more economically profitable in those troubled times.
\end{abstract}

KEY WORDS: embryology; bacteriology; Jaime Pujiula Dilmé; Joan Puiggrós Sala; $20^{\text {th }}$ century.

Copyright: () 2014 CSIC. Este es un artículo de acceso abierto distribuido bajo los términos de la licencia Creative Commons Attribution-Non Commercial (by-nc) Spain 3.0. 


\section{INTRODUCCIÓN}

El estudio de una disciplina científica requiere un conocimiento detallado de los espacios en los que se cultivó en un determinado momento. La historia de los centros de investigación, de los actores que pasaron por sus salas y del ambiente e influencias que recibieron, son indispensables para entender los entresijos del desarrollo de una especialidad. Para el caso de la embriología española del siglo XX resulta indispensable referirse a Jaime Pujiula y a su laboratorio, el Institut Biològic de Sarrià (IBS). Y es que, a pesar de tener unos intereses davincianos dentro del campo de la biología, este jesuita es conocido fundamentalmente por sus trabajos en embriología. Durante años, los dos tomos de su tratado se convirtieron en un imprescindible para las bibliotecas de los hispanoparlantes interesados en la especialidad, y durante el primer tercio de siglo, el Biológico fue prácticamente el único foro de investigación y docencia embriológica del país.

La figura de Jaime Pujiula ha sido abordada en algunos estudios previos desde el punto de vida biográfico (Durfort, 1995; Pujiula i Ribera, 2010; Teixidor, 2012). De hecho, su presencia en el debate evolucionismoantievolucionismo de principios de siglo lo ha convertido en protagonista de varios trabajos dedicados al problema (Pelayo, 2002; Blázquez Paniagua, 2005; Blázquez Paniagua, 2009; Catalá Gorgues, 2010). Menos atención se le ha prestado a su laboratorio. Su funcionamiento interno ha pasado casi desapercibido para la historiografía científica hasta el momento.

Así pues, el objetivo principal de este trabajo será el estudio del IBS desde su fundación hasta su desaparición definitiva. Se analizarán las razones por las que dejó de ser el centro de referencia de la embriología a nivel nacional y por las que se terminaron promoviendo otras especialidades como la microbiología. Asimismo, se intentará proponer una periodificación de la historia del centro alrededor de las profundas crisis (políticas, científicas y personales) que se vio obligado a sufrir durante su existencia.

Para estudiar a fondo estas vicisitudes internas recurrimos al Arxiu Històric de la Companyia de Jesús de Cataluña (AHSIC). Entre sus fondos se custodian dos unidades archivísticas de gran interés para nuestro trabajo: una dedicada al Padre Pujiula y otra que lleva por nombre Institut Biològic de Sarrià. La primera consta sólo de dos cajas, pero conserva todo el epistolario del jesuita e incluye una autobiografía mecanografiada aún inédita. El segundo fondo es mucho más extenso. Entre una gran cantidad de documentación económica, en esta unidad se puede localizar parte de la correspondencia del padre Puiggrós, uno de los más estrechos colaboradores de Pujiula y su sucesor al cargo del IBS. Sus cuadernos de laboratorio, así como los proyectos de reforma que planeó para el centro se conservan en el mismo fondo.
Los datos recogidos de este archivo se completaron con fuentes orales. En este caso, citamos la entrevista que realizamos en enero de 2010 a Josep María Domènech Mateu (n. 1944), catedrático de anatomía de la Universitat Autònoma de Barcelona, que mantuvo cierta relación de amistad con el P. Puiggrós y con otros morfólogos catalanes de la época.

\section{EL INSTITUT BIOLÒGIC DE SARRIÀ: FUNDACIÓN Y PRIMEROS AÑOS}

La vida de Jaime Pujiula Dilmé comenzó en la villa gerundense de Besalú en 1869. Según sus memorias ${ }^{1}$, el ambiente familiar resultó propicio para que tomase los hábitos, por lo que a los dieciocho años ingresó en el colegio de la Compañía en Veruela (Zaragoza). Aquel centro estaba especializado en humanidades y filosofía, así que pudo adquirir una sólida base humanística. La orden, no obstante, no descuidaba la formación científica de sus jóvenes; sus colegios mantenían unos interesantes gabinetes de ciencias naturales, física y química que eran cuidados con esmero por algunos padres dedicados exclusivamente a la ciencia.

La formación internacional de Pujiula comenzó muy temprano. Ingresó en la orden en 1887 y ya en 1893, con tan sólo veinticuatro años, viajó a Holanda para estudiar Filosofía. Después fue destinado al Colegio de San José de Valencia, donde coincidió con uno de los primeros discípulos de Cajal en aquella ciudad, el también jesuita Antonio Vicent Dolz (1837-1912). Las dotes de Pujiula para defenderse con el alemán, lengua de la ciencia del momento, fueron suficientes para que la Compañía viera en él un digno candidato a suceder a Vicent como experto en ciencias biológicas.

La primera tarea que se le encomendó fue hacerse cargo de las clases de Historia Natural del colegio. Para ello, en sus ratos de ocio se fue formando en Ciencias, adquiriendo un vasto, aunque estrictamente libresco, saber biológico. Una vez terminada la carrera, en 1906, el Provincial le propuso salir de nuevo al extranjero para ampliar conocimientos biológicos. Tras unas consultas por carta a los biólogos más importantes de la orden, Pujiula decidió dirigirse para ello a la Universidad de Innsbruck, en el Imperio Austrohúngaro.

Allí tuvo la oportunidad de estudiar zoología con el profesor Karl Heider (1866-1935), autor de un importante manual de embriología de invertebrados. Pero la biología del joven religioso tenía ya una clara vocación generalista, así que se preocupó por formarse en otras especialidades, como la botánica. Asimismo, aprovechando las vacaciones entre semestres, se trasladó a Trieste (Italia) y tomó contacto con las investigaciones embriológicas de Carl Isidor Cori (1865$1954)^{2}$, con quien participó activamente en sus experimentos sobre las primeras fases del desarrollo del erizo de mar. 
Desoyendo el consejo de Heider, que pretendía enviarlo a Friburgo a estudiar con Theodor Boveri (1862-1915) ${ }^{3}$, su siguiente parada fue -ya a finales de 1907-, el Embryologisch-histologische Institut de Hans Rabl (1868-1936) en Viena, una decisión que marcó profundamente su embriología, ya que Boveri estaba totalmente inmerso en la naciente embriología experimental ${ }^{4}$, una rama de la disciplina que Pujiula nunca llegó a conocer en la práctica.

Allí trabajó con Siegmund von Schumacher (18721944), que trataba el tema de la embriología del aparato urogenital; compartió laboratorio con Victor Widakowich (1880-1930), histólogo y embriólogo y, por aquellos años, asistente de Rabl; y entabló relación con otros muchos científicos que trabajaban en aquellos años en la ciudad (Von Ebner-Rofestein, Schäffer, Linsbauer, Exner...).

En 1908 terminó un trabajo de investigación sobre las células redondas (Die Frage der Riesenzelle bei der Entwicklung der Maus $^{5}$ ) y creyó tener capacidad suficiente para investigar por su cuenta ${ }^{6}$. El Provincial entendió que su formación había acabado y le instó a regresar. En España, instaló su primer laboratorio con la primitiva intención de formar en Biología a sus hermanos de la orden. El nuevo centro, conocido como el Laboratorio Biológico del Ebro, se estableció en la localidad tarraconense de Roquetas, donde los jesuitas tenían ya en marcha otros dos institutos de investigación ${ }^{7}$ (un observatorio meteorológico y astronómico y un laboratorio químico). De este modo, con la fundación del Biológico, la Compañía completó un interesante parque científico.

Los microscopios para iniciar los trabajos los trajo el mismo Pujiula desde Viena. En sus memorias recuerda:

Antes, pues, de volver a España y teniendo en cuenta la formación de un Laboratorio, compré varios microscopios: desde luego dos para discípulos [,,,]. Luego, o algo más tarde, el microscopio polarizador; también un microscopio simple, dos micrótomos, el de Rocking (usado en Cambrg) (sic) y el de Gebrüder Frohmann: el primero para parafina y el segundo para celoidina. Tambie'n se compró pronto el dispositivo del llamado ultramicroscopio [...] Ya el P. Dedeu [...] había comprado el mejor microscopio de Zeiss ${ }^{8}$.

Durante aquellos primeros años, una serie de conferencias bastaron para dar a conocer la recia personalidad del director del nuevo centro. Enfrentado con Haeckel, con su monismo y, por supuesto, con su Ley Biogenética Fundamental, Pujiula se convirtió en el adalid del antitransformismo en nuestro país. Sus tesis se opusieron firmemente a la transición entre especies, aunque nunca negó la adaptación morfológica dentro de los estrictos límites de la especie ("evolución especigenética") ${ }^{9}$.
En 1916, el laboratorio se trasladó a Barcelona y se ubicó en el Colegio de Sant Ignasi, una institución docente de los jesuitas en Sarrià, y fue rebautizado como Institut Biològic de Sarrià. Durante los años siguientes, comenzó una intensa labor como investigador y como docente que llegó a su punto más alto durante la Dictadura de Primo de Rivera. En estas fechas llegó a la presidencia de la Institució Catalana d'Història Natural (Camarasa, 2000, p. 68) y publicó su conocida Embriología del hombre y demás vertebrados (1923), el primer-y durante años, el único- tratado de la disciplina en castellano.

\section{LA LLEGADA DE PUIGGRÓS Y LA CRISIS DE LA II REPÚBLICA}

Con la llegada de la Segunda República, el laboratorio vivió en primera persona el ataque del gobierno azañista a la Compañía. Los bienes de la orden fueron confiscados, y a principios de 1932 el jesuita se vio obligado a abandonar su laboratorio. Pero los contactos de Pujiula eran muchos y pronto encontró asilo. La Societat Médico-farmacèutica dels Sants Cosme i Damià de Barcelona, una asociación decimonónica de ideología católica, cedió a los jesuitas unos edificios en la céntrica calle Llúria y allí se instalaron (Fig. 1). Aunque la situación resultó francamente traumática, permitió que se produjeran algunos cambios importantes, como la incorporación de las mujeres como alumnos ${ }^{10}$.

De una manera coherente, Pujiula formó parte activa de la asociación con la que había firmado el acuerdo. Intervino en muchas de las discusiones científicas que allí se celebraban y les aportó sus conocimientos embriológicos ${ }^{11}$. Asimismo, comenzó a impartir cursos sobre materias biológicas diversas y se embarcó en un ambicioso curso especializado en "embriología del hombre y de los vertebrados", cuya primera edición tuvo lugar entre el 2 de mayo y el 15 de junio de 1932.

Las clases prácticas eran parte fundamental de aquellos cursos, una característica que marcó una gran diferencia con la docencia oficial que se impartía en la pobre universidad catalana del primer tercio de siglo. El programa especificaba que los alumnos tendrían "36 días de trabajo: cada uno de ellos con una hora de lección oral y cuatro horas y media de prácticas de laboratorio"12, lo que suponía un intensivo adiestramiento en lo más básico de la ciencia embriológica.

Además, hasta el laboratorio de Llúria llegaban otro tipo de investigadores que, en el argot de la institución, se denominaban "especialistas". Estos eran científicos que, según consta en los programas, se acercaban al Biológico "a estudiar o investigar por cuenta propia; ora para ampliar conocimientos o técnicas, como v.g. tesis doctorales". Tras el corres- 
Figura 1. Laboratorio de Pujiula en la Sociedad Médico-Farmacéutica de los Santos Cosme y Damián. Folleto propagandístico de los años 30. Fuente: AHSIC

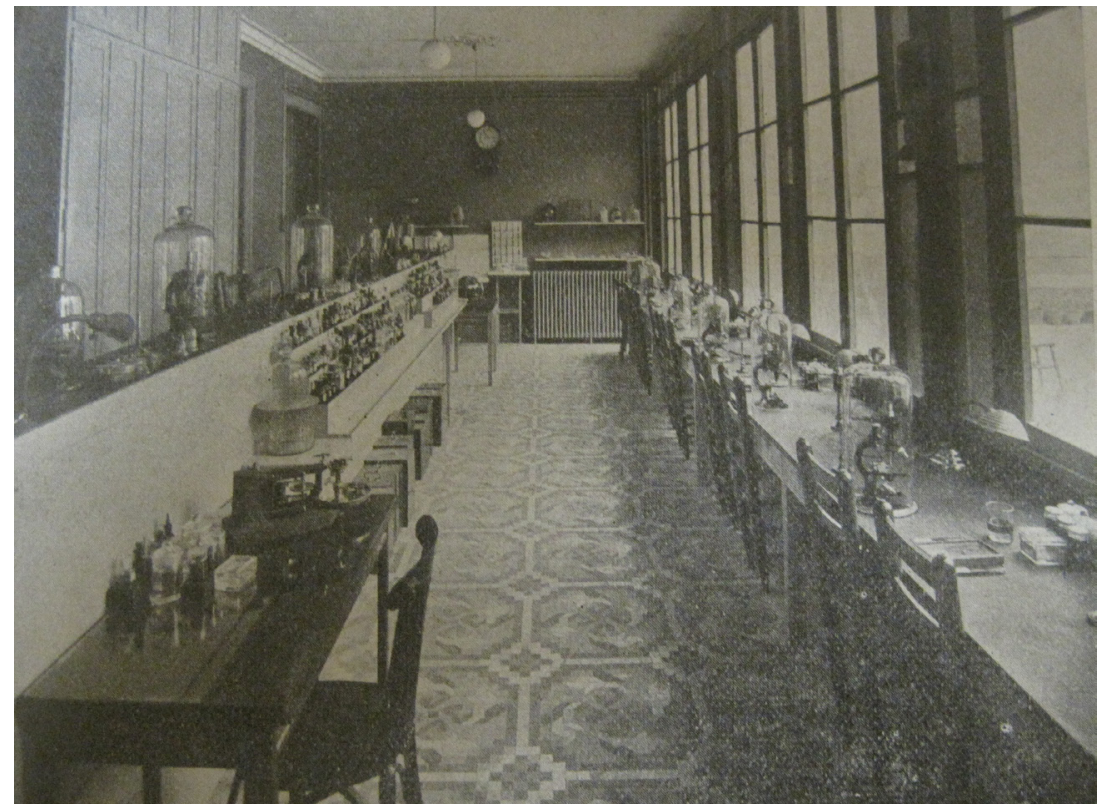

pondiente pago de matrícula, -125 pesetas mensuales-, estos investigadores adquirían el derecho a ser dirigidos en sus trabajos por el personal de laboratorio y a usar sus instalaciones durante unos horarios predeterminados ${ }^{13}$.

Esta vocación docente hizo que, más que un laboratorio de producción de nuevos conocimientos, el instituto se comportara como un centro de formación de investigadores. De hecho, nombres de reconocidos morfólogos de la época, como Rafael Alcalá Santaella (1896-1959), Salvador Gil Vernet (1892-1987) o Manuel Taure Gómez (1903-1979), aparecen en la lista de alumnos del centro. La falta de una línea de investigación propia y la rápida renovación de la plantilla de investigadores impidieron la creación de lo que entendemos como escuela a la sombra de Pujiula.

De lo que sí podemos hablar, sin embargo, es de colaboradores. Entre ellos destacaron dos que dedicaron casi toda su vida al Instituto: el Padre Puiggrós y el Padre Pertusa. El primero en llegar al Biológico fue Joan Puiggrós Sala (1899-?) quien, a pesar de especializarse más tarde en otros campos de la biología, comenzó, como no podía ser de otra forma, con la embriología. Sus primeros contactos con el laboratorio se remontan al verano de 1922, cuando acudió por primera vez a los cursos del maestro. Durante los siguientes veranos, dedicó sus vacaciones a dichos cursos y terminó convirtiéndose en el auxiliar del director y en el responsable de los trabajos de microfotografía ${ }^{14}$.

En 1930 fue ascendido a subdirector y, siguiendo los pasos de Pujiula, se trasladó a Centroeuropa para completar su formación. La gran afluencia de alumnos al IBS en aquellos años y la consecuente bonanza económica permitieron que aquel viaje pudiera ser sufragado por el propio Instituto ${ }^{15}$. En Alemania cursó la carrera de Ciencias Biológicas y posteriormente se trasladó hasta Viena para especializarse en embriología. Allí trabajó con Georg Politzer ${ }^{16}$ en el Institut für Histologie und Embriologie de Alfred Fischel y realizó una serie de trabajos descriptivos sobre el desarrollo del pulmón en embriones humanos ${ }^{17}$. En 1936, consiguió el título de doctor y regresó a España.

Durante aquellos años, el laboratorio fue abriéndose paulatinamente a nuevos alumnos. Acudían al centro estudiantes de ingeniería agrónoma y, por supuesto, de medicina. El objetivo de crear generaciones de médicos dotados de una formación científico-teológica era una máxima del IBS, por lo que este aspecto era cuidado especialmente. Durante las vacaciones de Navidad de 1935, por ejemplo, Pujiula impartió un curso de embriología a alumnos del segundo curso de medicina. En uno de sus informes mensuales al Padre Provincial, afirmaba que el curso había sido solicitado expresamente por los propios estudiantes y que estos se quejaban de que "no habían entendido casi nada en las explicaciones de la Facultad"18. Con estas acusaciones queda bien patente que el IBS se había afianzado como una herramienta de calidad que ofrecía un necesario apoyo a la universidad durante aquellos años. No obstante, resulta sorprendente tal grado de crítica a quien fue uno de sus discípulos, Manuel Taure. De hecho, el catedrático estaba haciendo un gran esfuerzo por integrar la docencia de la embriología 
-una materia que en el resto del país era responsabilidad de los histólogos- en la Anatomía Il y por implantar la obligatoriedad de unas prácticas embriológicas en esta asignatura.

En 1936 encontraron unos nuevos locales en la calle Bailén, en el mismo ensanche barcelonés. Aquel año, tan sólo dos doctorandos trabajaban junto a Pujiula. Uno terminó su trabajo poco después del traslado, mientras que el segundo se vio obligado a interrumpir momentáneamente sus investigaciones porque en el laboratorio no había espacio físico suficiente para convivir con los alumnos de los cursillos estivales ${ }^{19}$. Con este dato se podría crear la falsa idea de que cada verano llegaban al Biológico decenas de estudiantes. Nada más lejos de la realidad. A finales de la República no sólo escaseaban los candidatos al doctorado, sino que el número de alumnos se alejaba cada vez más de las multitudes que había conocido el IBS en tiempos pasados. Las nuevas instalaciones de Bailén no debían ser muy amplias cuando estaban colapsadas por los diez alumnos ${ }^{20}$ que estaban inscritos en estos cursos.

\section{EL EXILIO Y LA POSGUERRA}

El estallido de la Guerra Civil -recordaba Pujiula"destruyó todo nuestro porvenir"21. Ayudado por el cónsul de Colombia, el religioso huyó hacia Italia en barco y dejó el laboratorio en manos de Puiggrós. El 9 de agosto de 1936 estaba ya desembarcando en Génova ${ }^{22}$, y allí conoció al padre José Pertusa Gas (19061983), un alicantino "tercerón que habían mandado a Avigliana durante la cuaresma"23. Comenzó a colaborar con Pujiula y pronto le comunicó su interés por visitar algún centro extranjero para terminar su formación embriológica. A pesar de que se le aconsejó ir a Alemania, "como parece que él tenía mucha prisa, -recordaba Pujiula- optó por ir a Lovaina" 24.

El exilio terminó en junio de 1939 y a su regreso, el jesuita encontró su laboratorio totalmente destrozado. Puiggrós se había hecho cargo del mismo durante el conflicto, pero, tras tres años de guerra, el estado del edificio era ruinoso y había sido desvalijado. La intensa labor de recuperación del instrumental se alargó durante meses. Los primeros microscopios -entre ellos el apreciado de luz polarizada- fueron encontrados muy pronto. Junto a una gran cantidad de reactivos, algunos de ellos se encontraban almacenados en una torre del cementerio de Sarrià, formando parte de un conato de laboratorio que el gobierno republicano había intentado erigir durante la Guerra para la Escuela Superior de Agricultura ${ }^{25}$. La búsqueda no terminó allí y, aunque no consiguieron recuperar todo el material, aún apareció alguna pieza más. El relato pormenorizado de Pujiula nos ofrece un magnífico inventario del laboratorio antes de estallar la Guerra:

El microscopio Zeiss, que era el número uno en perfección óptica no estaba allí; pero quiso Dios que un
Farmacéutico de Blanes nos avisase que había en Blanes un microscopio que sospechó sería nuestro. [...] Fuimos con el P. Puiggrós a buscarlo. Se perdieron completamente el monobinocular de Zeiss que yo había adquirido, el monobinocular de Reichert que el P. Puiggrós había traído de Viena [y] tres o cuatro microscopios nuevos o casi nuevos. Los microproyectores, los microscopios simples todos desaparecidos, lo mismo que el Bituni de Zeiss y el Tamín ${ }^{26}$.

Asimismo, consiguieron rescatar buena parte de la biblioteca y la colección de preparaciones microscópicas que se habían depositado en el departamento de agricultura de la escuela de ingeniería industrial.

Deshecho el acuerdo con la Hermandad de San Cosme y San Damián, volvieron al edificio de Sarrià. Obviamente, el ahorro económico era la razón de más peso a la hora de tomar tal decisión, pero Pujiula tuvo en cuenta otra serie de beneficios directos. El local era mucho más amplio y, además, allí podría volver a trabajar al lado de sus colegas dedicados a la Filosofía y a la Teología, algo provechoso dada la ligazón de sus trabajos con estas materias ${ }^{27}$.

No obstante, para los superiores de la Orden la viabilidad del laboratorio era más que dudosa. Lo que comenzó como una crisis clásica de posguerra, se convirtió en un lastre que el IBS tuvo que arrastrar durante décadas. Aquel primer bache era tan sólo el comienzo de un período de déficits económicos y personales y de una lucha continua por la supervivencia del viejo proyecto personal de Pujiula.

La situación afectó directamente a la embriología, que fue perdiendo su puesto en el Biológico al mismo ritmo que Pujiula iba perdiendo su poder absoluto. Ante el envejecimiento de su mentor, Puiggrós se erigió como director de facto $y$, acorde con su perenne preocupación por la economía del centro, desplazó sus intereses hacia materias claramente más rentables -como era la microbiología aplicaday creó un laboratorio especializado en levaduras y fermentación (Fig. 2).

Además, tomó otra serie de decisiones para conseguir la recuperación del estatus perdido. Una de sus medidas más inmediatas consistió en ganar estudiantes ampliando la oferta original. Junto a los ya clásicos cursos de verano, se comenzaron a ofertar otros nuevos dedicados también a la embriología pero dirigidos de manera exclusiva a los estudiantes de Medicina de la Universidad de Barcelona. Pujiula seguía encargándose de los estivales ayudado por Puiggrós, mientras que de estos nuevos "de apoyo" se encargaba exclusivamente Puiggrós.

Estos se desarrollaban durante todo el primer trimestre y consistían en una hora diaria de teoría y dos de prácticas. Sin embargo, nunca se volvió a conseguir el éxito que los cursos habían tenido antes del período 
Figura 2a y 2b. Laboratorio de bacteriología (fermentaciones) del Padre Puiggrós. Fuente: AHSIC
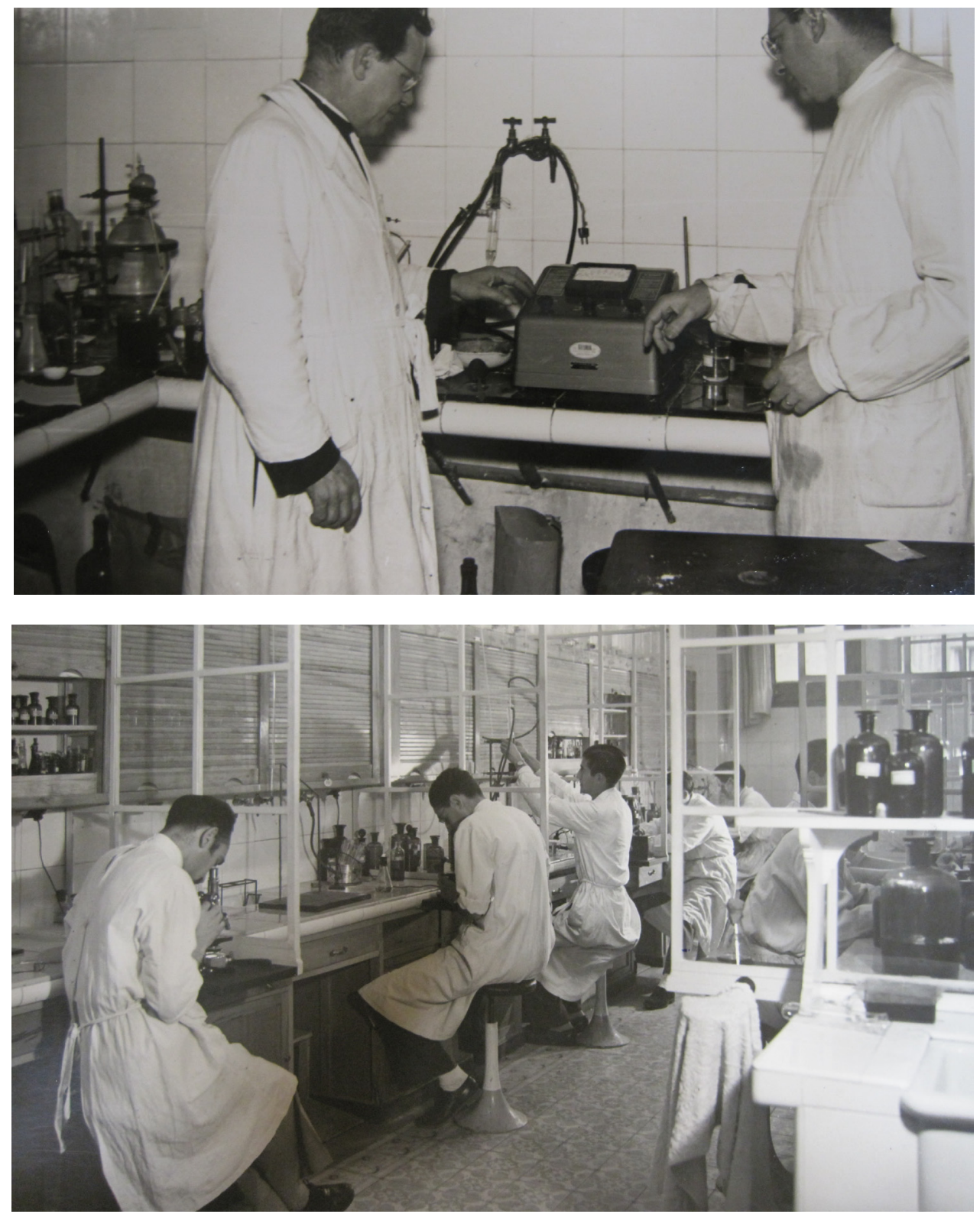

republicano. Pertusa le recordaría años más tarde a Puiggrós:

Usted recordará lo que ha estado pasando desde que abrimos el laboratorio después de la guerra. Es verdad que algunas veces se apuntaron 5 ó 6; pero ¿cuántos de ellos venían a clase? ¿y cuántos años no se apuntaron más de 3 ó 4 y después no venían más que 1 ó 2 ? [...] Recuerde usted que antes de la República sí que tenían su razón de ser [los cursos de verano], porque en el plan de Primo de Rivera se exigían prácticas en el Bachillerato, y al cogerlos desprevenidos era cuando tantos religiosos de otras órdenes acudían a estos cursos $^{28}$
La edad del director era asimismo un problema cada vez más acuciante. Pujiula se iba acercando a los 80 , lo que hizo que comenzaran a rodar informes sobre la conveniencia de que siguiera en su puesto. De hecho, a Puiggrós se le había ofrecido ser su sustituto hacía años -en 1939-, pero entonces rehusó entendiendo que Pujiula podía ejercer aún el cargo ${ }^{29}$. A finales de la década de los 40 la situación era bien distinta a los ojos del candidato a la sucesión. En enero de 1947 escribía:

el actual Director es ya incapaz. Que debe seguir siendo rey hasta la muerte, pero no puede ya ser rey absoluto responsable, por lo dicho antes. Hay que 
ponerle un Subdirector o ministro presidente responsable. De lo contrario será imposible este desarrollo progresivo que posibilite la supervivencia y el no lejano florecimiento del Instituto Biológico ${ }^{30}$.

El Provincial no se puso en contacto con Pujiula hasta febrero del año siguiente pero, ante las insinuaciones sobre el asunto, la respuesta del recio director fue tajante: "ni el P. Puiggrós ni el P. Pertusa pueden por ahora suplirme" ${ }^{31}$. Pujiula entendía que eran muchos los proyectos que tenía en marcha y que le sería imposible controlarlos todos sin estar él al frente ${ }^{32}$. Sin embargo, la situación era grave y desde la superioridad decidieron tomar medidas. Aquel mismo año se nombró a Puiggrós encargado de la parte económica del Instituto y a Pertusa de la administrativa ${ }^{33}$. La coyuntura, sin embargo, siguió siendo desbordante. Los informes sobre Pujiula son duros y reflejan crudamente al personaje en sus últimos años de vida: "Se encabrita y desprestigia", "lo quiere todo a su disposición", dice frases en público como "aquí mando yo"...

Con este carácter, Pujiula no permitía que el Padre Pertusa se formara a su lado, lo que impedía cualquier oportunidad de continuidad de sus trabajos embriológicos. El Instituto, referente otrora de la investigación embriológica del país, se fue quedando desfasado a pesar de contar con interesantes novedades técnicas que no se encontraban en cualquier laboratorio español de la época. Puiggrós nos relata:

Para restituir indiscutiblemente la Escuela de Embriología a la cabeza de todas las de España como le toca, disponemos de un aparato de modelaje único en España y de los pocos (3 ó 4 más) del mundo; a medio instalar porque el actual director, como él no trabajó con él al formarse, no lo aprecia, y así no se ha podido usar, mientras otros en España trabajan ahora mejor que aquí con supletorios rudimentos del mismo ${ }^{34}$.

Pero, ¿a quién se refería Puiggrós con "otros en España"? El anterior párrafo fue redactado en 1946 y por entonces Francisco Orts Llorca (1905-1993) ya había comenzado a crear una verdadera escuela de embriología desde su cátedra de Cádiz. El anatomista tampiqueño había comenzado a cultivar la embriología experimental junto a sus primeros discípulos ${ }^{35}$ y no existía otro centro en España que descollase en embriología aquel momento.

\section{UNA AUTORIDAD CASI CLÁSICA}

Sin embargo, y a pesar del arcaísmo de su embriología, Pujiula seguía siendo para muchos una especie de autoridad hierática por la que no pasaba el tiempo. Durante este período de posguerra siguieron llegando al IBS investigadores externos en busca de su tutela. Las becas de investigación para destinos nacionales no eran muy numerosas, pero los becarios interesados en embriología, no dudaban en acercarse a Sarrià.
Sabemos, por ejemplo, que durante estos años visitaron el Biológico un par de becarios procedentes del CSIC y de la Fundación "Conde de Cartagena". Hasta un científico internacional visitó el IBS durante la posguerra. La históloga Carla Zawisch-Ossenitz (18881961) ${ }^{36}$, procedente de Znojmo (Checoslovaquia), llegó a España tras ser perseguida por los ocupantes nazis de su país por motivos políticos. En Barcelona, encontró asilo en el laboratorio de Pujiula y, en la Universidad, se vinculó a la cátedra de anatomía de Taure como ayudante.

En 1943, ayudada por los jesuitas, Zawisch marchó a América por Portugal ${ }^{37}$. La históloga, sin embargo, nunca perdió el contacto con el jesuita. En 1946 regresó a Austria y al año siguiente consiguió la cátedra de Histología y Embriología de la Universidad de Graz. El recuerdo de la hospitalidad que encontró en Barcelona le llevó a forjar una íntima relación epistolar con Pujiula. Las notas de afecto y los recuerdos se entremezclan con las más variopintas cuestiones científicas en la correspondencia entre ambos. Pujiula aprovechaba para mandarle las separatas de sus publicaciones y ella, además de discusión, le proporcionaba bibliografía difícil de conseguir en España.

Esta científica encarna realmente la extensa red científica internacional a la que seguía perteneciendo Pujiula durante los años 40 . Un repaso al resto de la correspondencia del Padre nos muestra que durante estos años aún ejercía una buena influencia doctrinal en Sudamérica y Centroeuropa, no sólo sobre embriólogos, sino sobre investigadores de numerosas disciplinas biológicas que le enviaban cartas en busca de consejo o crítica $^{38}$.

La autoridad del jesuita en España tampoco vivía momentos bajos. En 1947 se le involucró en la creación de la Sociedad Anatómica Española (SAE) (Pascual Morenilla, 2000) formando parte de la primitiva comisión fundadora junto a Miguel Guirao Gea, catedrático de anatomía de Granada, y Alfredo Carrato Ibáñez, catedrático de Histología en Salamanca.

En diciembre de aquel año, Pujiula recibió de Guirao el anteproyecto de los estatutos de la asociación ${ }^{39}$ y en su línea intentó modificarlo intentando introducir en el texto fundacional la teleología de la morfología alemana que encerraba su embriología:

Tengo para mí que el título de la Sociedad debería ser este: Sociedad Española de Anatomía Razonada. La razón de este título es porque se quiere abrazar 1 o la anatomía descriptiva y topográfica; 2 ㅇ la razón de la disposición de los órganos: esta disposición obedece a dos causas: a) a la causa eficiente que es la Embriología, b) a la finalidad, o sea, a la causa final. En efecto todo órgano es así porque la evolución ontogénica así lo ha dispuesto, y es así porque responde a una finalidad, esto es, a una exigencia del organismo. Y el 
buscar la perfecta armonía del órgano con su función inquiriendo hasta el último detalle bajo este respecto es lo que más hace resplandecer la sabiduría del Creador. Todo esto digo porque así se tiene una Anatomía científica, como bien observó el Dr. Salvador Gil Vernet cuando vino a hacer en nuestro Instituto el curso de Embriología. La Anatomía, la Embriología y yo añado, sin buscar la finalidad, es una mera descripción, no es ciencia porque no da razón del por qué es así. Entran aquí los mismos fisiólogos ${ }^{40}$.

Aunque estas indicaciones no terminaron por cuajar en el texto final, la autoridad de Pujiula estuvo siempre muy presente en esta sociedad científica. De hecho, una vez aprobados los estatutos, se convirtió en su primer presidente.

\section{EL OCASO DE PUJIULA Y LA AMPLIACIÓN DEL IBS}

Pero la autoridad de Pujiula no corría paralela a su producción científica y la embriología seguía perdiendo peso en el laboratorio barcelonés. Desde 1942, sus publicaciones embriológicas se redujeron prácticamente a sus intervenciones en las sesiones de la Real Academia de Ciencias Exactas, Físicas y Naturales de Madrid (Pujiula 1942, 1943a, 1943b, 1945 1946a, 1946b, 1947, 1948, 1949a, 1949b, 1949c, 1953, 1955, 1956, 1957a, 1958a, 1958b, 1959, 1960a, 1960b), una serie de trabajos que dedicó a demostrar la bionomía embrionaria, un concepto con el que se refería a la diferencia morfológica del desarrollo de las diferentes especies desde el momento de la fecundación.

Su embriología -siempre al servicio de su eterna lucha contra el transformismo haeckeliano- seguía siendo comparativa y meramente descriptiva. Pero a estas alturas de siglo, las dos escuelas anatómicas dominantes, la de Francisco Orts Llorca y la de José Escolar García, tenían unas potentes líneas de investigación embriológica con un notable impacto internacional que desbancaban por completo la influencia regional del jesuita.

La microbiología de Puiggrós, por el contrario, terminó por afianzarse en el IBS gracias el respaldo del CSIC, que le creó una sección propia en 1947. La embriología ya tenía sus protegidos para la "ciencia oficial" del momento y en 1945 se había creado alrededor de la cátedra de Alfredo Carrato Ibáñez (19111994) en Salamanca una sección de "embriología experimental de tejidos". Además, como ha destacado Huertas García-Alejo, la microbiología y las fermentaciones fueron unas de las disciplinas biológicas más fomentadas de aquel primer CSIC (Huertas GarcíaAlejo, 2007, p. 296).

Desde luego, aquel apoyo oficial significó toda una inyección de vitalidad económica para el instituto, que hasta entonces vivía de las ventas de los libros de Pujiula, de las matrículas de los estudian- tes y de los negocios que Pertusa mantenía con la industria sedera ${ }^{41}$.

Durante los años siguientes, los ingresos y la dotación del laboratorio siguieron aumentando considerablemente. Sabemos, asimismo, que un investigador compró para el Biológico una bomba de vacío valorada en 5.000 pesetas, que se reeditó la Embriología de Puijula con gran éxito y que el CSIC no solamente proporcionó dinero, sino también instrumentación científica (una balanza de precisión, un autoclave...) -eso sí, en calidad de préstamo ${ }^{42}$.

Esta nueva situación dio pie a que Puiggrós diera rienda suelta a su imaginación y comenzara a planificar una ampliación del instituto. Además de adquirir nueva instrumentación y de arreglar la cuadra que servía de animalario, su proyecto recogía una notable reforma de los espacios destinados a la investigación; de hecho, el laboratorio de Sarrià seguía teniendo los mismos problemas de espacio que había tenido en los locales del ensanche. En el colegio contaban tan sólo con una sala para investigación con capacidad para 8 científicos y el nuevo plan pretendía habilitar dos con 16 ó 20 puestos.

Las trabas más importantes para el proyecto las pusieron el resto de institutos con los que compartían el edificio. El laboratorio de psicología experimental del Padre Fernando María Palmés, por ejemplo, ocupaba parte de las salas que antaño pertenecían al museo del Biológico, por lo que se veía directamente afectado por los planes de Puiggrós (Fig. 3). Sin embargo, la mayor y más beligerante oposición la encontró en el director del Instituto Químico, el Padre Salvador Gil. Sus instalaciones impedían por completo la expansión física de IBS y en las reformas que había realizado durante la posguerra, se había llevado por delante espacios que pertenecían históricamente al Biológico, como el jardín botánico. El enfrentamiento entre ambos fue de tal calibre, que trascendió a las autoridades de la Compañía.

La curia provincial no apoyó a Puiggrós y le ofreció como alternativa la ocupación de la Torre Villavecchia $^{43}$, otro de los inmuebles que los jesuitas poseían en Sarrià; pero para entonces ya habían comenzado las reformas en sus propias salas. Para ello, en 1950 Puiggrós solicitó un préstamo de 50.000 pesetas a una caja de ahorros ${ }^{44}$. Confiaba en que pudiera cubrirse con las entradas del siguiente curso ${ }^{45}$, pero las previsiones de ingresos no se cumplieron y poco después, ante lo apremiante de la deuda, se vieron obligados a solicitar otro préstamo por valor de 180.000 pesetas.

Pero esta crisis económica no parecía amedrentar a Puiggrós, que siguió planteando ampliaciones y reformas ${ }^{46}$. La escuela de fermentaciones que había puesto en marcha consumía su tiempo y se había em- 
Figura 3. Plano del Institut Biològic en Sarrià. Folleto propagandístico, 1940. Fuente: AHSIC

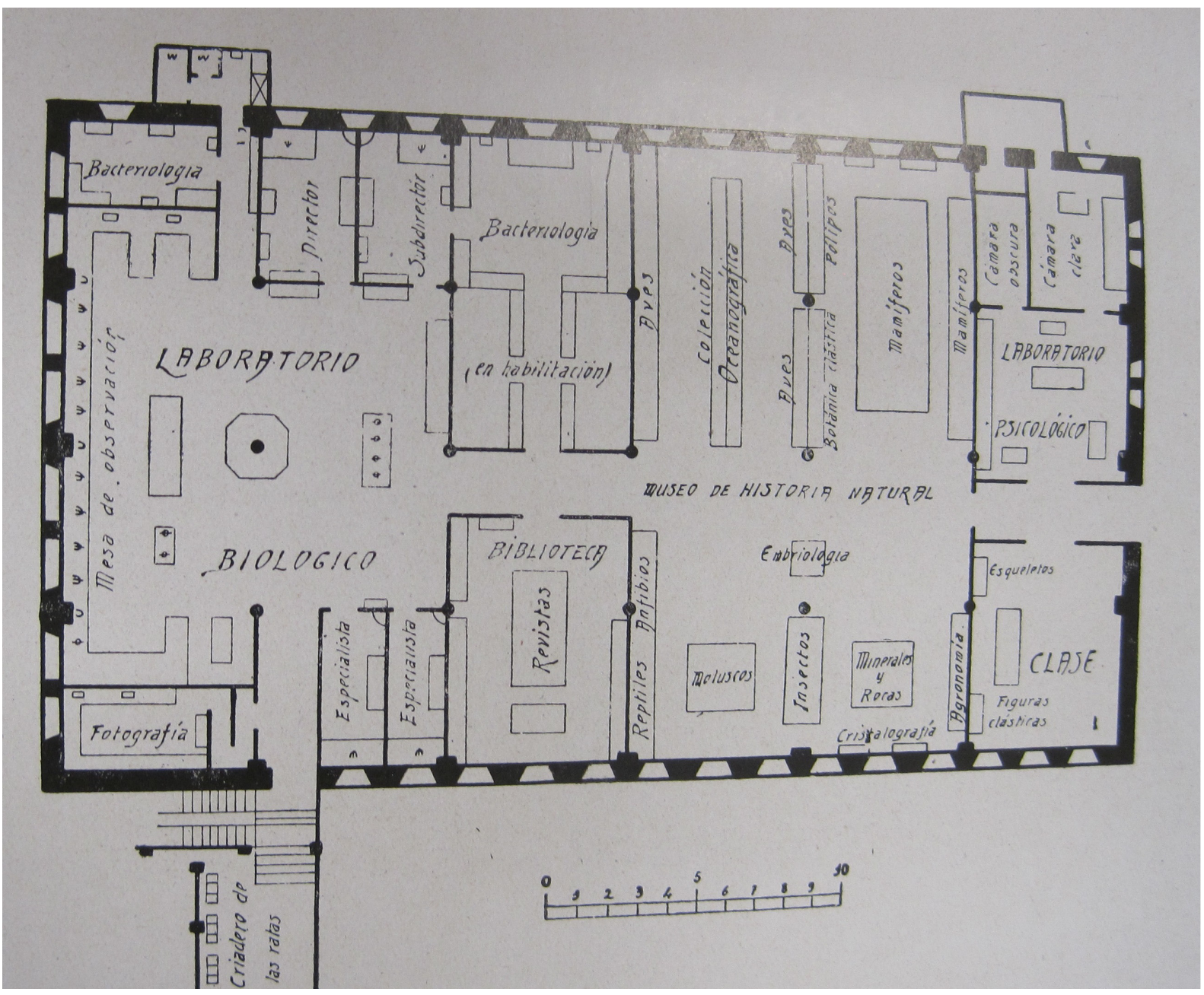

barcado en un ambicioso proyecto de creación de una titulación oficial de bacteriología. Cada vez con más fuerza, sus propios intereses científicos acaparaban la actividad del centro mientras que los de Pujiula -y con ellos, la embriología-, languidecían.

\section{LA EMBRIOLOGÍA DEL IBS DESPUÉS DE PUJIULA}

A finales de la década de los 50 se volvió a abrir el debate sobre la edad del director (Fig 4). Las intenciones del jesuita de seguir al frente del proyecto hasta su muerte se veían espoleadas por la cantidad de homenajes que le eran brindados. El 1 de noviembre de 1957, el propio Franco le entregaba la Gran Cruz de Alfonso X el Sabio. El anciano biólogo pretendía llevar el mismo ritmo de investigación que en su juventud y aquella actitud le estaba llevando a notorios fracasos. En 1956, por ejemplo, le fueron rechazadas por la Universidad de Barcelona tres tesis que había dirigido ${ }^{47}$. Preocupado por la repercusión de estos sucesos para el prestigio del IBS, Puiggrós terminó por elevar un informe demoledor:

Es dulcísimo trabajar a la sombra, despreciado de todos, menos cuando ello redunda, como estos últimos años, en peligro de ruina y muerte de la obra encomendada por la obediencia. ${ }^{48}$

Haciéndose cargo del asunto, mediante oficio fechado el 17 de mayo de 1958, los superiores de la Compañía nombraron a Puiggrós director del Instituto ${ }^{49}$. Sólo unos meses después, Pujiula enfermó gravemente de una enfermedad febril y el 15 de diciembre murió en el mismo colegio.

Las consecuencias del fallecimiento de Pujiula para un proyecto tan personal como el IBS no tardaron en aparecer. El Provincial de la Tarraconense, Víctor Blajot, aprovechó para volver a plantear la disolución del Instituto. El empeño de Puiggrós consiguió, sin embargo, que no se hiciera efectiva aquella decisión. Durante unos años más, el sucesor de Pujiula estuvo al 
Figura 4. El anciano Pujiula con Puiggrós y unos alumnos en el curso de fermentaciones de 1951. Fuente: AHSIC.

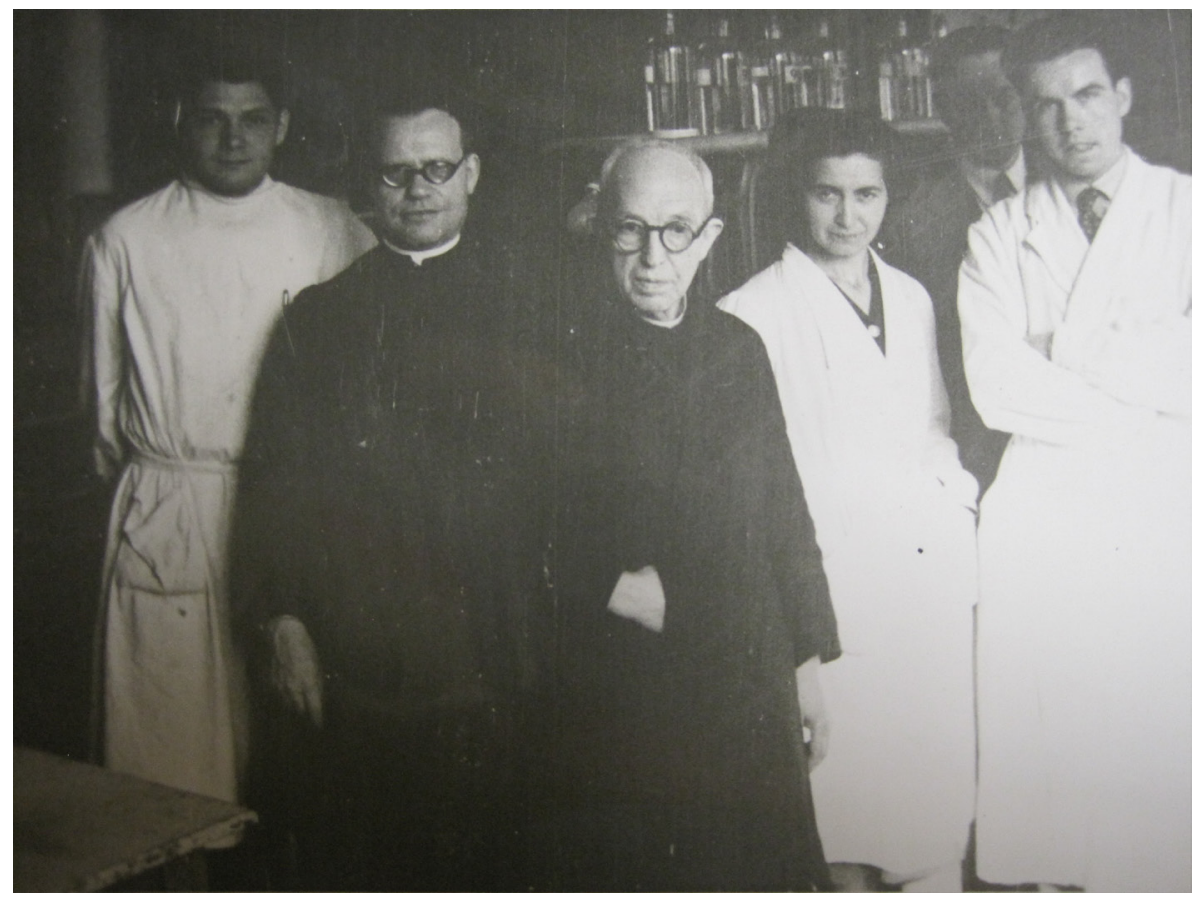

frente de una institución que siguió caracterizándose por la inestabilidad económica y la falta de personal.

Con Puiggrós atendiendo a otros asuntos, las esperanzas para la embriología estaban puestas en el Padre Pertusa. Con el fin de completar su especialización en esta materia se desplazó hasta Inglaterra y comenzó una serie de trabajos en el Departament of Anatomy and Embryology del University College of London. El departamento, dirigido por John Z. Young (1907-1997) ${ }^{50}$, tenía una potente línea de investigación embriológica, pero con unas características diametralmente opuestas a las que había propugnado Pujiula: la embriología experimental y el enfoque darwinista eran una constante de la morfología de Young ${ }^{51}$.

Cuando Pertusa llegó a aquel laboratorio, el británico estaba centrado en las neurociencias y tan sólo mantenía una pequeña línea de investigación embriológica sobre la estructura del tiroides fetal. El que estaba dedicado a la morfogénesis en aquel departamento era Michael Abercrombie (1912-1979), que se había formado en esta ciencia gracias a la tutela de Young y a la del maestro de éste, Gavin de Beer (1899-1972). Durante los últimos años, había hecho importantes descripciones sobre las funciones del nódulo de Hensen y del área pelúcida como estructuras inductoras y los resultados de aquellos experimentos le habían llevado a interesarse por las migraciones celulares durante el desarrollo ${ }^{52}$. En fin, una embriología experimental y actualizada, lejos de la que había mantenido Pujiula hasta aquellos años.
Por entonces Abercrombie trabajaba en trasplantes de tejidos de blastodermo de pollo cultivados y Pertusa, siguiendo esta línea, se dedicó a estudiar los movimientos morfogénicos de los jóvenes blastodermos. A su llegada a Londres informaba así al IBS:

[Abercrombie] me ha dado como tema de trabajo el marcar y trasplantar el nudo de Hense (sic). Este trabajo ya lo empecé a hacer, pero en plan de tanteo para ver si era posible. Ahora, como hemos visto que es una cosa realizable, lo tomaré en serio, y empleando fósforo radiactivo ${ }^{53}$.

A pesar de los intereses prioritarios a los que ya hemos hecho referencia, Puiggrós arrastraba desde hacía años la idea de "renovar y modernizar" la embriología del Biológico ${ }^{54}$, así que aquellas noticias le fueron tan gratas que incluyó en los planes de ampliación del instituto la creación de un laboratorio especializado en radioisótopos ${ }^{55}$. Pertusa terminó sus experimentos en 1961 y defendió su trabajo Studies on morphogenetic movements in the chick blastoderm, con el que consiguió el grado de doctor por aquella universidad.

Mientras tanto, en España, el IBS vivía en perpetua crisis económica y seguía en el punto de mira de los superiores de la Compañía. En plenos años 60, los gastos de un laboratorio competitivo a nivel internacional superaban con creces sus presupuestos, así que Puiggrós propuso varias soluciones basadas en la intensificación de la relación con la industria y con la universidad. Comenzó oficializando los clásicos cursos para estudiantes de medicina y diseñó un proyecto 
para convertir el Instituto en una especie de academia de educación superior ${ }^{56}$.

Pero sus planes iban mucho más allá. Si sus expectativas se cumplían, al igual que había pasado con el Estudio General del Opus Dei en Navarra, la nueva institución académica estaría llamada a convertirse en una nueva Universidad privada católica. Llegó a establecer contactos con el decano de la Facultad de Medicina e incluso buscó profesores para el nuevo centro. Para la asignatura de Histología y Embriología eligió a Diego Ferrer Fernández de la Riva (1901-1995), un histólogo catalán que desde 1941 ocupaba la cátedra de Cádiz. Según Puiggrós, estaba dispuesto a pedir una excedencia en su universidad para poderse trasladar al Biológico y adherirse al proyecto ${ }^{57}$. El plan, sin embargo, se desechó por varios motivos. No sólo adolecía de un patente problema económico, sino que la Universidad de Barcelona había propuesto que el director del estudio fuera un laico, algo que no agradó demasiado a los consultores de la curia.

Además de los problemas económicos, la falta de personal impedía el desarrollo del instituto. Cada vez resultaba más difícil encontrar jesuitas preparados en ciencias biológicas y Puiggrós puso toda su confianza en el Padre Alberto Gutiérrez Sancho (1920-1996), que estudiaba Medicina en Viena. Su condición de médico, una novedad para el IBS, hizo volar la imaginación del Director, que lo dibujó prematuramente ocupando la cátedra de Histología y Embriología de alguna universidad ${ }^{58}$. Sin embargo, una vez doctorado, el plan sufrió un revés. El joven jesuita optó por no colaborar con Puiggrós ${ }^{59}$ y con él desaparecieron todas las opciones de encontrar miembros de la Compañía capaces de perpetuar las actividades del laboratorio.

Ante tal situación, en 1965 se creó una comisión para informar al Provincial sobre el estado del laboratorio $^{60}$. El dictamen llegó al año siguiente. Para adaptarse a los tiempos se optó por fusionar el Instituto Biológico con el Químico y se creó una nueva sección de bioquímica; Pertusa se quedó en el Instituto y siguió con la línea de histología y embriología y Puiggrós fue destinado a Madrid (Durfort, 1985), donde siguió con sus trabajos sobre fermentaciones.

En 1966, Domingo Ruano Gil (n. 1932) consiguió una de las cátedras de anatomía de la Universitat de Barcelona. Como discípulo de Orts Llorca, trajo consigo una verdadera renovación de la enseñanza embriológica en la licenciatura (Sirvent, 2013). La vieja razón de ser del IBS como sustituto privado de una pobre docencia oficial, parecía llegar a su fin.

Los siguientes no fueron años de gran producción embriológica por parte del Biológico. Según el testimonio de Mercé Durfort, se iniciaron contactos con otros laboratorios embriológicos internacionales ${ }^{61}$, aunque no llegaron a establecerse lazos firmes. No obstante, a pesar de todas las inclemencias, el trabajo más relevante de Pertusa apareció en esta época (Pertusa, 1966) en el Journal of Embryology and Experimental Morphology, la revista del departamento de Abercrombie. La vinculación con su maestro británico seguía siendo, de hecho, muy estrecha. Es más, el material con el que trabajó durante aquellos años era importado desde Londres ${ }^{62}$.

Estos tímidos lazos nada tenían que ver con las conexiones internacionales de la escuela embriológica de Orts Llorca (Sirvent, 2013) o de la otra gran escuela morfológica que se había desarrollado en el país, la de José Escolar García (1913-1998) (Velasco Morgado, en prensa), que por entonces dominaban la investigación embriológica en España.

\section{CONCLUSIONES}

Al igual que había pasado durante el sexenio democrático, la pobre dotación de las facultades de medicina españolas permitió la germinación y auge de laboratorios privados que se ocuparan de la formación práctica de los estudiantes. Haciendo gala de una vocación centenaria de investigación y docencia, la Compañía de Jesús aprovechó este vacío oficial y creó un instituto biológico alrededor de la figura de Jaime Pujiula, a quien previamente habían enviado a Centroeuropa en busca de una formación especializada.

A su regreso, erigió un laboratorio con la primitiva intención de formar en ciencias biológicas a los miembros de la orden. La larga historia del centro, que mantuvo actividad hasta después de la muerte del fundador, está repleta de crisis. Los continuos cambios políticos de la primera mitad del siglo XX afectaron directamente a su rumbo. Tras el primer envite por parte del gobierno de la República en 1932, el laboratorio se fue adaptando a la situación ocupando diferentes locales en los que llevar a cabo su actividad. Pero las verdaderas dificultades vinieron tras la Guerra Civil. Nuestra investigación ha detectado tres factores determinantes que explican la extinción de la otrora brillante embriología del Biológico.

En primer lugar, y a pesar de seguir siendo un personaje de cierta importancia en círculos nacionales e internacionales, la edad de Pujiula permitió que su colaborador más cercano, el Padre Juan Puiggrós, se hiciera con el control del instituto e impusiera como línea principal de investigación su especialidad, la bacteriología aplicada. El apoyo del CSIC a esta otra línea -más rentable en términos económicos y más interesante para los barones del Consejo-, terminó por inclinar la balanza hacia esta disciplina.

Por otra parte, la personalidad del viejo director, recia y autoritaria, no propició la creación de una escuela embriológica a su alrededor. $Y$ esto a pesar del 
interés mostrado del Padre Pertusa, que superó la embriología comparativa de su maestro y se formó en embriología causal en Londres, en el laboratorio de John Young.

Por último, el auge de las escuelas anatómicas de Orts Llorca y Escolar hizo que no fuera necesario contar con laboratorios privados para las prácticas embriológicas. La embriología se fue convirtiendo progresivamente en una ciencia iatrocéntrica y el laboratorio de Sarrià se quedó fuera de estos círculos.

En fin, a pesar de los grandes esfuerzos de Pujiula, durante la segunda mitad del siglo, su embriología an-

\section{NOTAS}

1 Nos referimos al texto inédito: Jaime PUJIULA, Bosquejo histórico del origen y desarrollo del Instituto Biológico de Sarrià, (A partir de ahora, Bosquejo) Original mecanografiado. conservado en el AHSIC. Fondo Jaime Pujiula. p. 41.

2 No confundir con su hijo, Carl Ferdinand Cori, futuro premio Nobel por sus investigaciones bioquímicas, que es al que por error hace referencia Durfort, 1995, p. 832 y que por entonces aún era un niño.

3 AHSIC, Fondo Jaime Puijula, Bosquejo, p. 41.

4 Un acercamiento a la figura de Boveri en: Mortitz, 1996

5 El texto, publicado en lengua alemana (Pujiula, 1908) a pesar de presentarse a un encuentro en España, tuvo cierta repercusión a nivel internacional. Fue citado en varias obras de relevancia, aunque casi siempre a través de la cita que de él hizo Sobotta en uno de sus trabajos sobre la embriología de la rata (Sobotta, 1911).

6 Dice textualmente Pujiula en sus memorias: "Se iban a cumplir dos años de estar yo en el extranjero, trabajando en mi formación. [...] cuando yo juzqué que ya con buenos libros y revistas podría ir adelante solo, escribí al R.P. Provincial que era aún el P. Inesta para saber su voluntad". AHSIC, Fondo Jaime Puijula, Bosquejo, p. 24

7 Acerca del Observatorio del Ebro, véase García Doncel y Roca Rosell, 2007.

8 AHSIC, Fondo Jaime Puijula, Bosquejo, p. 26

9 Sobre las teorías antievolucionistas de Pujiula, véase Catalá, 2010.

10 AHSIC, Fondo Jaime Pujiula, Bosquejo, p. 41

11 A modo de ejemplo véase La Vanguardia, Año 51, no 21.522, 16 de febrero de 1933, p. 8.

12 "Vida Docente", en: La Vanguardia, Año 51, no 21.267, 24 de abril de 1932, p. 4. tihaeckeliana, tuvo que dejar paso a una embriología integrada en la anatomía holística -brausiana- que, con sus matices, traían consigo los discípulos de Orts y Escolar.

\section{AGRADECIMIENTOS}

Mi más sincero agradecimiento para el Prof. Antonio Carreras, que dirigió mi tesis doctoral -núcleo del presente trabajo- y para el personal del AHSIC, especialmente para el P. Francesc Casanovas, SJ, que hizo fácil la localización de documentos y, con ella, mi investigación.

13 Plan de Estudios del Laboratorio Biológico de la Sociedad Médico-Farmacéutica de los Santos Cosme y Damián (folleto impreso), Barcelona, s.d. s.f. Localizado en AHSIC. Fondo IBS.

14 AHSIC. Fondo IBS. Currículum vitae de Juan Puiggrós Sala enviado a la Fundación Juan March junto a una solicitud de ayuda, 26 de noviembre de 1971.

15 AHSIC. Fondo Padre Pujiula. Bosquejo, p. 73. Este mismo relato autobiográfico nos cuenta cómo Pujiula aprovechó el buen momento económico para hacer un viaje científico por toda Europa junto con uno de sus doctorandos, Antonio Vendrell Martí, el año 1933.

16 Según el Josep María Domènech: “[Puiggrós] dirige inicialmente sus estudios de investigación en el campo de la embriología, se traslada a Viena y el profesor Politzer le acoge con gran cariño. De esta relación tengo información directa a partir del profesor Pons Tortella". Entrevista con Josep María Domènech Mateu (n. 1944), 27 de enero de 2010.

17 Su resumen fue publicado al año siguiente (Puiggrós, 1936)

18 AHSIC. Fondo Padre Pujiula. OB 1.1. Correspondència. Carp. 1936-1947. Pujiula a José Mạ Murall, S.J. (Padre Provincial). [Barcelona], 15 de enero de 1936

19 AHSIC. Fondo Padre Pujiula. OB 1.1. Correspondència. Carp. 1936-1947. Pujiula a José Mạ Murall, S.J. (Padre Provincial), [Barcelona], 13 de julio de 1936.

20 Seis inscritos en embriología y cuatro en histopatología. AHSIC. Fondo Padre Pujiula. OB 1.1. Correspondència. Carp. 1936-1947. Pujiula a José Ma Murall, S.J. (P. Provincial), [Barcelona], 13 de julio de 1936

21 AHSIC. Fondo Padre Pujiula. Bosquejo, p. 42.

22 AHSIC, Fondo Padre Pujiula, Bosquejo, pp. 42-50.

23 AHSIC, Fondo Padre Pujiula, Bosquejo, p. 51. 
24 AHSIC, Fondo Padre Pujiula, Bosquejo, p. 51.

25 AHSIC, Fondo Padre Pujiula, Bosquejo, p. 52

26 AHSIC, Fondo Padre Pujiula, Bosquejo, p. 54.

27 AHSIC. Fondo Padre Pujiula. OB 1.1. Correspondència. Carp. 1936-1947. Pujiula al R.P. Alfredo Mondría S.J. (Padre Provincial). [Barcelona], 21 de diciembre de 1939.

28 AHSIC. Fondo Jaime Pujiula. Correspondència. [EI P. Pertusa al P. Puiggrós] Londres, s.f.

29 AHSIC. Fondo del IBS. Sin cat. Carta de Puiggrós al P. Julián Sayos, S.J. Barcelona, 20 de mayo de 1950

30 AHSIC. Fondo IBS. Sin.cat. Carta de Puiggrós al P. Cándido Mazón S.I. [Barcelona], 27 de enero de 1947.

31 AHSIC. Fondo IBS. Correspondència. Carp. Cartas P. Director [P. Pujiula]. Antes de 1950. Pujiula al R.P. Cándido Mazón, S.J. (P. Provincial) [Barcelona], 9 de febrero de 1948.

32 AHSIC, Fondo P. Pujiula. Correspondència. Carp. Cartas P. Director [P. Pujiula]. Antes de 1950. Pujiula al R.P. Cándido Mazón, S.J. (P. Provincial) [Barcelona], 9 de febrero de 1948.

33 AHSIC. Fondo IBS. OB 1.1. Correspondència. Carp. Cartas P. Director [P. Pujiula]. Antes de 1950. Pujiula al R.P. Julián Sayós, (Padre Provincial), [Barcelona], 20 de septiembre de 1948.

34 AHSIC. Fondo IBS. OB 1.1. Correspondència. Carp. 1936-1947. Plan de reorganización del Instituto Biológico de Sarrià. Lo que parece de posible realización para el año próximo y principio de su desarrollo ulterior. [Juan Puiggrós, 1946]

35 Un primer acercamiento bio-bibliográfico a la figura de Orts en: Aréchaga, Juan, Jiménez-Collado, Juan y Ruano Gil, Domingo (2009).

36 Sobre la biografía de Carla Zawisch véase Kernbauer, 2011.

37 "Nunca olvidare lo que han hecho para (sic) mi", aseguraba. AHSIC. Fondo Padre Pujiula. Correspondència. Carta de Carla Zawisch a Pujiula, Lisboa, 4 de julio de 1943.

38 Un ejemplo claro de esta influencia durante el período de la posguerra es la labor de formación biológica del padre jesuita Emanuel Cándido Rondon do Amarante (1915-1982), para quien Pujiula tenía planeado que creara un laboratorio similar al IBS en su Brasil natal. Aunque Amarante cultivaría más otras áreas de la Biología como la Botánica, en Sarrià se curtió en todas las especialidades que manejaba Pujiula y, entre otras cosas, hizo acopio de una colección de preparaciones embriológicas que se llevó a Brasil. Consúltese AHSIC. Fondo Padre Pujiula. Correspondència. Carta de Pujiula al Provincial Arturo Alonso. Sin lugar, sin fecha.

39 Según Pascual Morenilla y colaboradores, estos estatutos eran una adaptación de los de la Sociedad Anatómica Portuguesa enviados a Guirao por Henrique de Vilhena. Sobre la formación de estos estatutos, a lo que añadimos esta aportación inédita de Pujiula, véase Pascual Morenilla, 2000, pp. 12-15.

40 AHSIC. Fondo IBS. Correspondència. Carta de Pujiula a Miguel Guirao Gea, [Barcelona, sin fecha, en respuesta a otra de Guirao fechada en 27 de diciembre de 1947].
41 En una aproximación del curso 46-47, se hablaba de 25.000 pesetas anuales de la sección del CSIC, 10.000 de la sección de sericultura de Pertusa dependiente del Sindicato Sedero de Orihuela. Los ingresos provenientes de las matrículas sumaban 29.100 pesetas y las ventas de los libros de Pujiula unas 3.000. AHSIC. Fondo IBS. OB 1.1. Correspondència. Carpeta. 19361947. Plan de reorganización del Instituto Biológico de Sarrià. Lo que parece de posible realización para el año próximo y principio de su desarrollo ulterior. [Juan Puiggrós, 1946].

42 AHSIC. Fondo IBS. OB 1.1. Correspondència. Carp. Cartas P. Director [P. Pujiula]. Antes de 1950. Pujiula al R.P. Provincial Julián Sayós, S.J. [Barcelona], 20 de septiembre de 1948.

43 Aquel problema llevó a Puiggrós a un enfrentamiento personal con el Padre Julián Sayós. Sobre el tema: AHSIC. Fondo IBS. OB 1.1. Correspondència. Carp. Cartas particulares (1950-1955).

44 La mayor suma - 60.000 pesetas- se invirtió en su laboratorio de fermentaciones y con el resto se reformó la biblioteca, la clase y los demás laboratorios.

45 AHSIC. Fondo IBS. OB 1.1. Correspondència. Carp. Cartas particulares (1950-1955). Razones para pedir prestadas a la Caja de Ahorros 50.000 petas. Por fianza de 10 bienhechores, [Puiggrós, Barcelona,] 19 de octubre de 1950.

46 Para lograr sus fines llegó proponer que el Instituto se embarcara en un nuevo crédito de 600.000 pesetas. Consúltese AHSIC. OB 1.1. Institut Biològic de Sarrià. Correspondència. Carp. Cartas particulares (1950-1955).

47 AHSIC. OB 1.1. Institut Biològic de Sarrià. Correspondència. Carp. Cartas particulares (1950-1955). Carta de Puiggrós al Padre Provincial, [sin fecha ni lugar]

48 AHSIC. Fondo IBS, OB 1.1. Correspondència. Carp. Cartas particulares (1950-1955). Carta de Puiggrós a la superioridad. [Sin fecha ni lugar]

49 AHSIC. Fondo IBS, OB 1.1. Correspondència. Carp. IBS, Carp. Cartas P. Director (1956-1960). Carta sin firmar dirigida a Puiggrós, 17 de mayo de 1958.

50 Para contextualizar el laboratorio véase la autobiografía de Young (Young, 1996).

51 Young, 1996, p. 558.

52 Véase su biografía en Bellairs, 2000

53 AHSIC, Fondo IBS, OB 1.1. Correspondència. Carp. Información sobre IBS (1959-1960), Carta de Pertusa a Puiggrós Londres, s.d.

54 AHSIC, Fondo IBS, OB 1.1. Correspondència. Carp. IBS varia (1956-1960). Idea sucinta del plan de desarrollo del Instituto Biológico de Sarrià, Barcelona, 13 de octubre de 1960.

55 Ya en 1956, fecha en la que Pertusa estaba formándose ya en Inglaterra, se le recomendaba desde el IBS: "Conviene que se forme bien en toda la técnica de la experimentación con radioactivos, tanto para embriología como para las demás ramas de la biología. En cuanto vuelva espero que se podrá montar el laboratorio especializado de radioactivos". AHSIC, Fondo IBS, Sin cat. Carta [de ¿Puiggrós?] a Pertusa, Barcelona, 30 de noviembre de 1956. 
56 Los estudiantes pagaban una tasa de 300 pesetas por asignatura y obtenían el derecho a las clases prácticas que no podía ofrecer la Universidad.

57 AHSIC, Fondo IBS, OB 1.1. Correspondència. Carp. IBS varia (1956-1960). Idea sucinta del plan de desarrollo del Instituto Biológico de Sarrià, Barcelona, 13 de octubre de 1960.

58 AHSIC, Fondo IBS, OB 1.1. Correspondència. Carp. IBS varia (1956-1960, Carta de Puiggrós, no consta destinatario, sin lugar, 27 de enero de 1959.

59 Según Puiggrós, por no tener "una orientación clara". AHSIC, Fondo IBS, OB 1.1. Correspondència. Carp. Información sobre
IBS (1959-1960), "Instituto Biológico de Sarrià", 8 de febrero de 1965 .

60 AHSIC, Fondo IBS, OB 1.1. Correspondència. Carp. Información sobre IBS (1959-1960), "Instituto Biológico de Sarrià", 8 de febrero de 1965.

61 Durfort (1985) cita el dirigido por Giuseppe Reverberi (19031988), un italiano, también sacerdote, experto en embriología.

62 Pertusa, 1966. p. 131

\section{REFERENCIAS BIBLIOGRÁFICAS}

Aréchaga, Juan, Jiménez-Collado, Juan y Ruano Gil, Domingo (2009), "A glance at Spanish Embryology and Teratology during the XX Century through the academic life of Francisco Orts-Llorca (1905-1993)", International Journal of Developmental Biology, 53: 1165-1177.

Bellairs, Ruth (2000), “Michael Abercrombie (1912-1979)”, International Journal of Developmental Biology, 44: 23-28.

Blázquez Paniagua, F.B. (2005), "Notas sobre el debate evolucionista en España (1900-1936)", Revista de Hispanismo Filosófico, 12, pp. 23-44.

Blázquez Paniagua, F.B. (2009), "La recepción del darwinismo en la universidad española (1939-1999), Anuario de Historia de la Iglesia; 18, pp. 55-68.

Camarasa, Josep M. (2000), Cent anys de passió per la Natura : Una història de la Institució Catalana d'Història Natural, 1899-1999, Barcelona: Institució Catalana d'Història Natural.

Català Gorgues, Jesús I. (2010), “Notícies i idees sobre l’origen, antiguitat i evolució de l'home a la revista Iberica", Actes d'Història de la Ciència i de la Tècnica, Nova época, 3(1), pp. 49-61.

Corbella, Jacint (1996), Història de la Facultat de Medicina de Barcelona. 1843-1985, Barcelona, Fundació Uriach 1938.

Durfort i Coll, Mercé (1985), “L’Institut Biològic de Sarrià i la Institució Catalana d'Història Natural", Butlletí de I'Institució Catalana d'Història Natural, 50, pp. 67-73.

Durfort i Coll, Mercé (1995), “Jaime Pujiula I Dilmé, SJ. La morfología microscópica”. En: Camarasa, J.M. y Roca Rosell, A. (dirs.), Ciència i técnica als Països Catalans. Una aproximació biográfica als darrers 150 anys, Barcelona, Fundació Catalana per a la Recerca, pp. 829-858.

García Doncel, Manuel y Roca Rosell, Antoni (2007), Observatorio del Ebro: un siglo de historia (1904-2004), Roquetas: Observatori de l'Ebre.

Huertas García-Alejo, Rafael (2007), "Las ciencias biomédicas en el CSIC durante el franquismo". En: Puig-Samper Mulero, Miguel Ángel (Coord.), Madrid, CSIC, pp. 293-298.
Kernbauer, Alois "Zawisch-Ossenithz Carla, Histologin", Biografia, Biografische datenbank und lexikon österreichischer frauen [en línea], disponible en: http://www.univie.ac.at/biografiA/daten/ text/bio/zawisch-o_c.htm, [consultado el 20/11/2011].

Mortitz, Karl B. y Sauer, Helmut W. (1996), "Boveri's contributions to developmental biology -a challenge for today", International Journal of Developmental Biology, 40: 27-47.

Pascual Morenilla, María Teresa, Guirao Piñeyro, Miguel y Girón Irueste, Fernando, (2000), La Sociedad Anatómica Española y los anatómicos españoles del siglo XX. Libro conmemorativo del 50 ㅇ aniversario de la $S A E$, Granada: Editorial Comares.

Pelayo, Francisco, (2002), "Darwinismo y antidarwinismo en España (1900-1939): la extensión y crítica de las ideas evolucionistas". En: Puig-Samper, M, Ruíz, R y Galera, A. (eds.), Evolucionismo y Cultura. Darwinismo en Europa e Iberoamérica, Junta de Extremadura y Universidad Nacional Autónoma de México, pp. 267-284.

Pertusa, José, (1966) "A simple technique for the preservation of vital dyes in fixed and sectioned embryos", Journal of Embryology and Experimental Morphology, 15(2): 131-132.

Puiggrós Sala, Joan (1936), "Über die Entwicklung der Lungenanlage des Menschen", Z. Anat. Entw. Gesch.,106, pp. 209-225.

Pujiula, Jaime (1909), “Die Frage der Riesenzelle bei der Entwicklung der Maus", Primer congreso de naturalistas españoles. Actas y memorias, Zaragoza.

Pujiula, Jaime (1923), Embriología del hombre y de los demás vertebrados, Barcelona, Pujiula. 2 vols.

Pujiula, Jaime (1942), "Las células redondas y gigantes del hígado embrionario, su origen y destino", Revista de la Real Academia de Ciencias Exactas, Físicas y Naturales de Madrid, 36(1), pp. 92-104.

Pujiula Jaime (1943a), "Revisión de algunos datos científicos relacionados con la ontogénesis y la Bionomía embrionaria", Revista de la Real Academia de Ciencias Exactas, Físicas y Naturales de Madrid, 38(3 y4), pp. 79-89. 
Pujiula, Jaime (1943b), "Papilas del hocico y carrillos en embriones de Sus escrofa domesticus parecidas a esbozos de glándulas mamarias" Real Academia de Ciencias Exactas, Físicas y Naturales de Madrid, 38(1), pp. 47-56.

Pujiula Jaime (1945), "Confirmación de las leyes hematopoyéticas del hígado embrionario relacionadas con el saco vitelino y la placenta", Revista de la Real Academia de Ciencias Exactas, Físicas y Naturales de Madrid, 39(3 y 4), pp. 411-419.

Pujiula, Jaime (1946a), "La actividad hormonal del huevo", Revista de la Real Academia de Ciencias Exactas, Físicas y Naturales de Madrid, 40, pp. 439-448.

Pujiula, Jaime (1946b), "Aportación a la bionomía embriológica", Revista de la Real Academia de Ciencias Exactas, Físicas y Naturales de Madrid, 41(2), pp. 177-187.

Pujiula, Jaime (1947), “Aportación a la bionomía embriológica”, Revista de la Real Academia de Ciencias Exactas, Físicas y Naturales de Madrid, 41(2), pp. 177-187.

Pujiula, Jaime (1948), "Revisión de algunos datos científicos relacionados con la ontogénesis y la bionomía embrionaria", Revista de la Real Academia de Ciencias Exactas, Físicas y Naturales de Madrid, 42(5), pp. 79-90.

Pujiula, Jaime (1949a), "Discronicidad relativa en la formación de algunos órganos en Embriología comparada", Revista de la Real Academia de Ciencias Exactas, Físicas y Naturales de Madrid, 1949, 43, pp. 227-230.

Pujiula, Jaime (1949b), “Dependencias embrionarias del embrión humano: el saco vitelino y el corion con sus vellosidades", Revista de la Real Academia de Ciencias Exactas, Físicas y Naturales de Madrid, Memorias, 10, pp. 365-380.

Pujiula, Jaime (1949c), "Dependencias embrionarias del embrión humano: el saco vitelino y el corion con sus vellosidades", Revista de la Real Academia de Ciencias Exactas, Físicas y Naturales de Madrid, Serie Segunda, 10, pp. 365-380.

Pujiula, Jaime (1949d), “Datos bionómicos especialmente sobre la relación cefalocórmica (en embriones)", Archivo Español de Morfología, 1949; 23, pp. 183-192.

Pujiula, Jaime (1953), "Trayectorias bionómico-embriológicas", Revista de la Real Academia de Ciencias Exactas, Físicas y Naturales de Madrid, 47, pp. 241-247.

Pujula, Jaime (1955), "Datos observados en el embrión humano de cuatro-seis semanas traído por el Dr. Nubiola para su estudio", Revista de la Real Academia de Ciencias Exactas, Físicas y Naturales de Madrid, 49(4), pp. 383-386.

Pujiula, Jaime (1956), "Ganglios espinales escindidos en un embrión humano", Revista de la Real Academia de Ciencias Exactas, Físicas y Naturales de Madrid, 50(4), pp. 531-533.

Pujiula, Jaime (1956-1957), “Contribución al conocimiento de la organogénesis del ojo de Perdix nita (perdiz)", Archives Portugaises des Sciences Biologiques, 8(1/2), pp. 133-137.
Pujiula, Jaime (1957a), "Un surco dorsal medio en un embrión humano de dos meses, abortado", Revista de la Real Academia de Ciencias Exactas, Físicas y Naturales de Madrid, 51(2), pp. 185-191.

Pujiula, Jaime (1957b), "El plexo coroideo en el embrión humano de 8 meses abortado", Anales de Medicina y Cirugía, 37(140), pp. 87-89.

Pujiula, Jaime (1958a), "Las glándulas salivares en el embrión de Mus musculus (ratita) de 17 días", Revista de la Real Academia de Ciencias Exactas, Físicas y Naturales de Madrid, 52(1), pp. 87-91.

Pujiula, Jaime (1958b), "El paniculus adiposus en la espalda de un embrión de rata", Revista de la Real Academia de Ciencias Exactas, Físicas y Naturales de Madrid, 52(2), pp. 389-390.

Pujiula, Jaime (1959), "Más sobre las células redondas del hígado", Revista de la RAC de Madrid, 53(3), pp. 649-652.

Pujiula, Jaime (1960a), "El tejido mesenquimatoso vacuolizado en Cricetus cricetus L. (hámster)", Revista de la Real Academia de Ciencias Exactas, Físicas y Naturales de Madrid, 54(1), pp. 161-164.

Pujiula, Jaime (1960b), "Bionomia placentaria", Revista de la Real Academia de Ciencias Exactas, Físicas y Naturales de Madrid, 54(2), pp. 168-298.

Pujiula i Ribera, Jordi (2010), “P. Jaime Pujiula i Dilmé (18691958). Els límits entre la Ciència i la Filosofia”, Gimbernat, 53, pp. 195-209.

Teixidó Gómez, Francisco (2011), “El jesuita Jaime Pujiula Dilmé, científico clave de la investigación biológica barcelonesa", Llull, Revista de la Sociedad Española de Historia de las Ciencias y de las Técnicas, 34(73), pp. 203-228.

Sobotta, J. (1911), "Die Entwicklung des Eies der Maus vom ersten Auftreten des Mesoderms an bis zur Ausbildung der Embryonalanlage und dem Auftreten des Allantois. I. Teil: Die keimblase" Arch. F. Mik. Anat., 78.

Sirvent Ribalda, Enric (2013), Del cuerpo regional a la totalidad viviente: Saber y prácticas anatómicas de las Ciencias de la Salud en Barcelona 1960-2012, Tesis doctoral, Tarragona: Universitat Rovira i Virgili, [en línea] disponible en: http://www.tdx.cat/handle/10803/119536 [consultado el 2 de diciembre de 2013].

Victori i Companys, Lluis (2008), “Introducción”. En: Pujiula, Jaime, Elementos de Embriología, [Ed. Facsímil], Barcelona, IQS.

Velasco Morgado (En prensa), “Embriología y 'ciencia oficial'. La aportación de la escuela anatómica de José Escolar a la embriología durante el Primer Franquismo (1939-1959)", Dynamis, Acta Hispanica ad Medicinae Scientiarumque Historiam Illustrandam.

Young, John Z (1996), "John Z. Young”. En: Squire, Larry S. (ed.), The history of Neuroscience in autobiography, Vol. 1, Washington D.C., Society for Neuroscience, pp. 554-586. 